\title{
Study of characteristics of steel specimens after selective laser melting of powder materials MS1
}

\author{
Anton Zhukov ${ }^{1, *}$, Boris Barakhtin ${ }^{1}$, and Artem Deev ${ }^{1}$ \\ ${ }^{1}$ NRC "Kurchatov Institute" - CRISM "Prometey", 191015, Saint-Petersburg, Russia
}

\begin{abstract}
At present, there is a great interest in the technologies of laser melting of metallic powders for the any shape items production. Over the past decade, the process of selective laser melting (SLM) of various powders based on alloys and steels was mastered. However, not so long ago, many studies were aimed at SLM stainless steels, including MS1 steel. The effect of laser radiation power, scanning speed, pitch, building direction on the microstructure and mechanical properties of the final product is studied. The influence of the parameters of the initial material, such as the chemical composition, the shape and size of the particles, and their distribution is indicated. Since the SLM process is sensitive to building parameters it is necessary to obtain more information about the mechanical and structural properties of standard samples in order to better understand the capabilities of this technology.
\end{abstract}

\section{Introduction}

In recent decades, selective laser melting of stainless steel powders has received much attention [1-4]. Data have become widely in demand in various industries, and the manufacture of products from powder materials is quite a promising direction.

As the object of investigation, maraging steel MS1 was chosen in this work. A special interest in this brand is that, in contrast to the austenitic steels, which are quite common for use in the SLM process, alpha-gammaalpha phase transition takes place. Numerous investigations have revealed a number of features of the structure and properties of powdered martensitic steels [5-7]. It is established that there is an anisotropy of the mechanical properties with respect to the building parameters. This is due to the peculiarities of the grain structure - the grains are more elongated in the building direction than across the building direction [8].

In this connection, it seems important to try to find out whether it is possible, by changing the parameters of melting, to achieve a lower anisotropy.

The aim of the work was to study the structure, mechanical properties and the nature of the fracture surface of standard samples made of maraging steel powders MS1 by the method of selective laser melting (SLM) under different laser parameters. The purpose of the study is to determine the influence of the building parameters on the anisotropy of the mechanical properties of grown samples.

\section{Materials and experimental methods}

The raw material used is the powder of maraging stainless steel MS1, manufactured by EOS GMBH
(Germany). The chemical composition of the powder, determined by X-ray fluorescent analysis methods on the Niton XL3t and LECO CS744 units, is shown in Table 1, from which it is seen that it complies with the ASTM A 240 standard.

Table 1. Chemical composition of used powders.

\begin{tabular}{|c|c|}
\hline \multicolumn{2}{|c|}{ Basic alloying elements, \% by weight } \\
\hline $\mathrm{C}$ & 1,0 \\
\hline $\mathrm{Si}$ & 0,1 \\
\hline $\mathrm{Mn}$ & 0,1 \\
\hline $\mathrm{Cr}$ & 0,28 \\
\hline $\mathrm{Ni}$ & 18,1 \\
\hline $\mathrm{Mo}$ & 5,3 \\
\hline $\mathrm{Co}$ & 9,3 \\
\hline $\mathrm{Ti}$ & 1,0 \\
\hline
\end{tabular}

The particle size distribution of the powder measured in the Malvern Mastersizer 2000 using the Fraunhofer approximation's laser diffraction method is shown in Figure 1. It can be seen that the MS1 steel powder has a large fractional composition, but a small amount of fine particles is present. In general, the powder meets the requirements for powders for SLM technology.

*Corresponding author: jouan2@gmail.com 


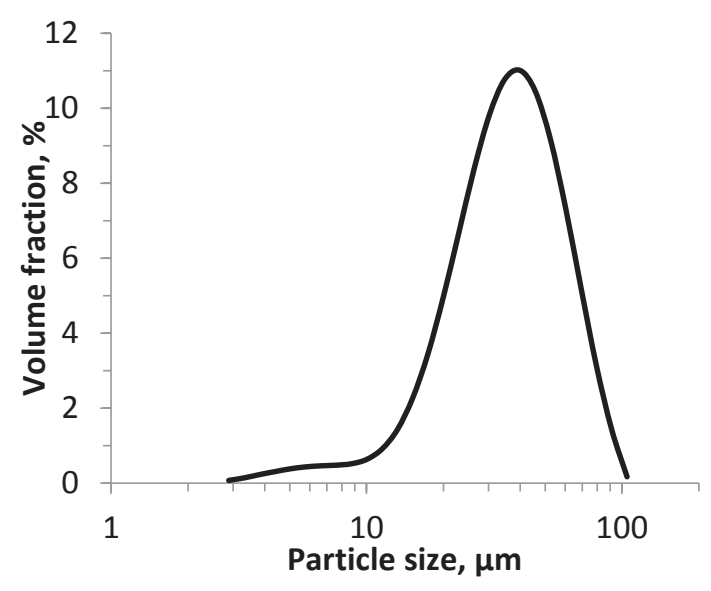

Fig. 1. The grain size distribution of MS1 steel powders.

Selective laser melting of powders was performed on the EOSINT M270 equipment. The powders were melted at $190 \mathrm{~W}$ and scanning speeds of $600,650,700$, $750,800 \mathrm{~mm} / \mathrm{s}$. The thickness of the melted powder's layer was $40 \mu \mathrm{m}$. For analyzing the effect of speed and power, a specific power value (in other words, the heat input) calculated as the Heat input $=$ Laser power $/$ Scan velocity $[\mathrm{W} \cdot \mathrm{s} / \mathrm{mm}]$ was used.

3D models for mechanical testing for tension, according ASTM E8, and impact strength, according ASTM D 6110, were designed to evaluate the structure and mechanical properties. It should be noted that the Ushaped notch of horizontal samples was implemented in the model. In addition, due to a large amount of samples, their numbering was done during the modeling. An example of manufactured samples is shown on the Figure 2.

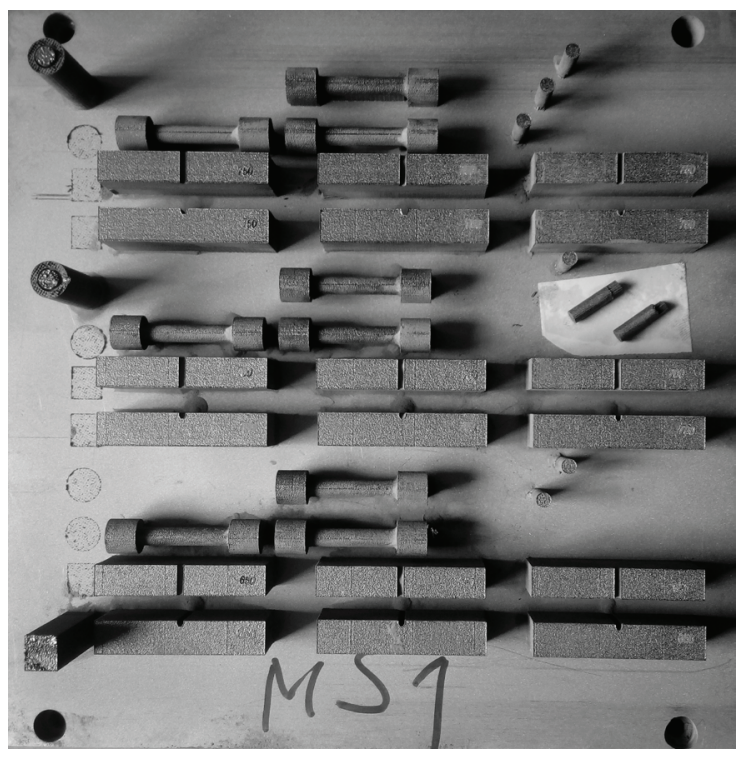

Fig. 2. Appearance of the built specimens on a platform.

Mechanical properties were determined at room temperature on a universal Zwick / Roell Z250 test machine and Metrocom-300 drop hammer, respectively. The hardness of the samples was determined using a Zwick / Roell ZHU 750 top.
The density of the samples was determined by the method of hydrostatic weighing on the analytical scales Mettler Toledo Excellence Plus XP.

Metallographic studies were performed on the optical microscope Axio Observer A1m with Clemex Vision PE computer program. Metallographic samples were made from impact strength samples. The etching of the surface to reveal the structure was carried out in a $10 \%$ aqueous solution of oxalic acid.

\section{Experimental results and discussion}

The measured values of the density and porosity of the samples are shown in Figure 3, from which it can be seen that both characteristics are close to the characteristics of the MS1 steel samples obtained by traditional metallurgical technologies. The values obtained can be explained by the presence of a small number of pores and other inclusions.

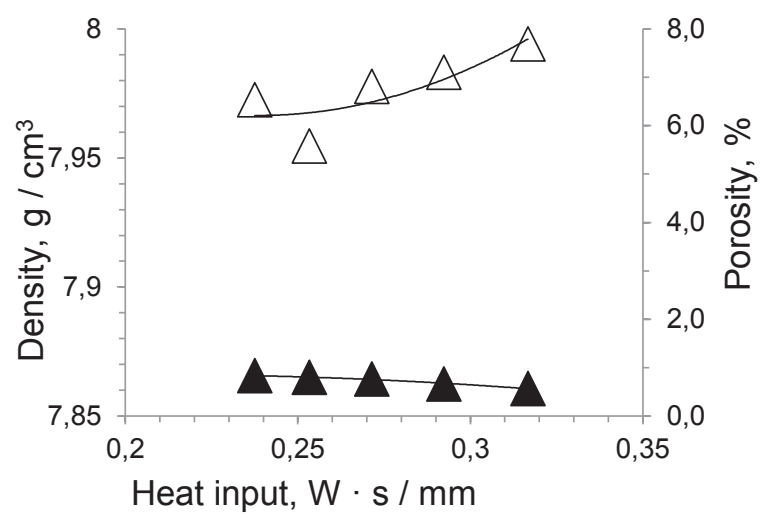

Fig. 3. Dependences of the density (open symbols) and porosity (painted symbols) of MS1 steel samples vs heat input.

It is known [9] that the strength properties of steels with "aging" martensitic, in which alpha-gamma-alpha phase transition takes place, increase with heat treatment after quenching. In our case, the material obtained by melting was subjected to annealing at a temperature of $490{ }^{\circ} \mathrm{C}$ for 1 hour.

Dynamic bending tests with fracture toughness assessment (Figure 4A) and failure performance (Figure 4B) showed that in the metal in the state "immediately after melting" (without annealing) the crack resistance is $20 \pm 5$ and $25 \pm 5$, respectively. The revealed differences are caused by the anisotropy of the macrostructure of the metal formed under different modes of sample building.

It was also found that with increasing energy deposition, the fracture toughness values do not decrease, but the effect of anisotropy practically disappears. The revealed features indicate an improvement in the powder's melting quality. However, it can be assumed that the observed tendency will be affected by the thickness of the deposited layer and the dispersion of the powder, since the quality of the melting is determined not only by the energy input, but also by the heat exchange between the particles. 

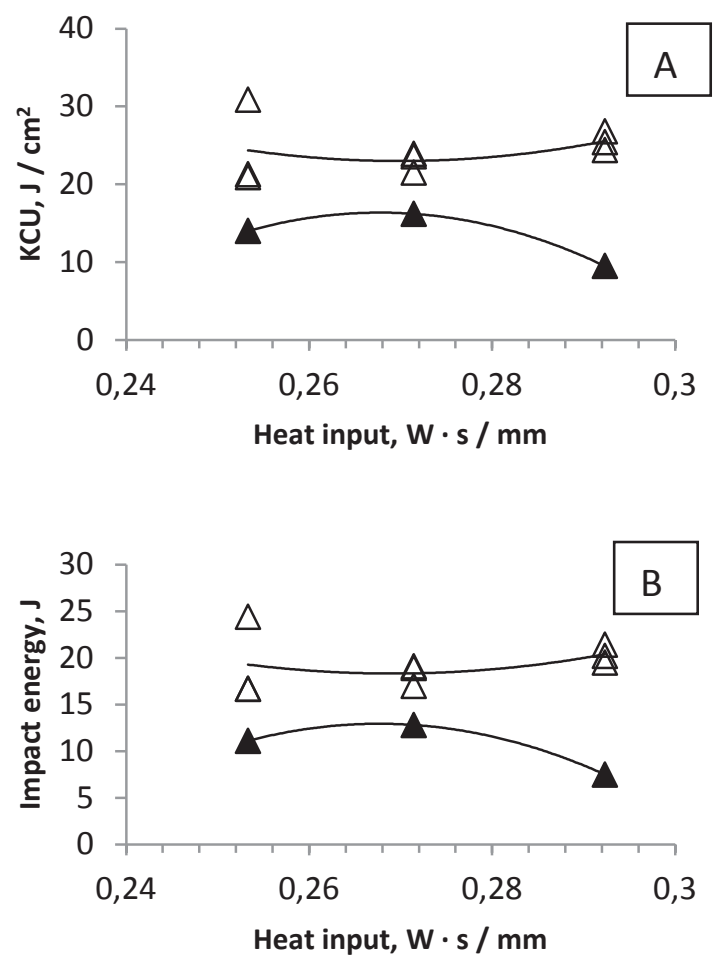

Fig. 4. Impact strength / KCU (A) and impact energy (B) of the test samples without annealing (open symbols) and after quenching (painted symbols).

Measurement of the hardness value on the faces of standard samples showed that this characteristic does not depend on the location of the preforms on the platform and varies exponentially with increasing heat input, reaching a maximum at a heat input of $\sim 0.27$ (Figure 5). The maximum hardness is about $350 \mathrm{HB}$, which is slightly higher than the standard values for this steel at $325 \mathrm{HB}$. After the annealing, the nature of the hardness dependence on the energy deposition did not change and the hardness numbers amounted to about $500 \mathrm{HB}$.

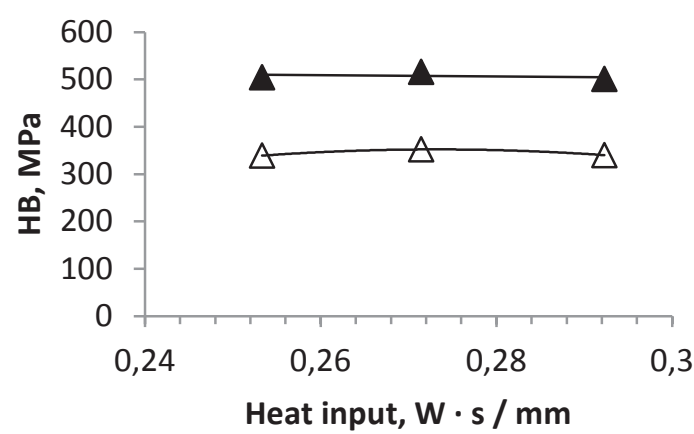

Fig. 5. Hardness of the test samples without annealing (open symbols) and after quenching (painted symbols).

As expected, after quenching, the strength of the metal increased, and the resistance to crack development decreased. In this case, the values of the viscosity were determined with a large spread for the samples created at a heat input of $\sim 0.27$. This fact allows us to assume that at a heat input of $\sim 0.27$ in the metal structure, the alloying elements (Mo, Co, Ti) are distributed so that dispersoids of different morphology and thermodynamic stability are formed during annealing, as it is known [10] that in maraging steels the hardening particles are $\mathrm{Ni}_{\mathrm{n}} \mathrm{Ti}_{\mathrm{m}}$ in the temperature range $300-400{ }^{\circ} \mathrm{C}$ and $\mathrm{Fe}_{\mathrm{p}}(\mathrm{Mo} \mathrm{Co})_{\mathrm{q}}$ at temperatures of $550-650{ }^{\circ} \mathrm{C}$. In complete agreement with the dynamic bend test data, the results of uniaxial stretching of the samples are found. It is established that the "traditional" complex of mechanical parameters $\left(\sigma_{0.2}\right.$, UTS, $\left.\delta\right)$ reaches a maximum with minimum variance (spread) after melting with heat input $\sim 0.27$ (Figure 6).
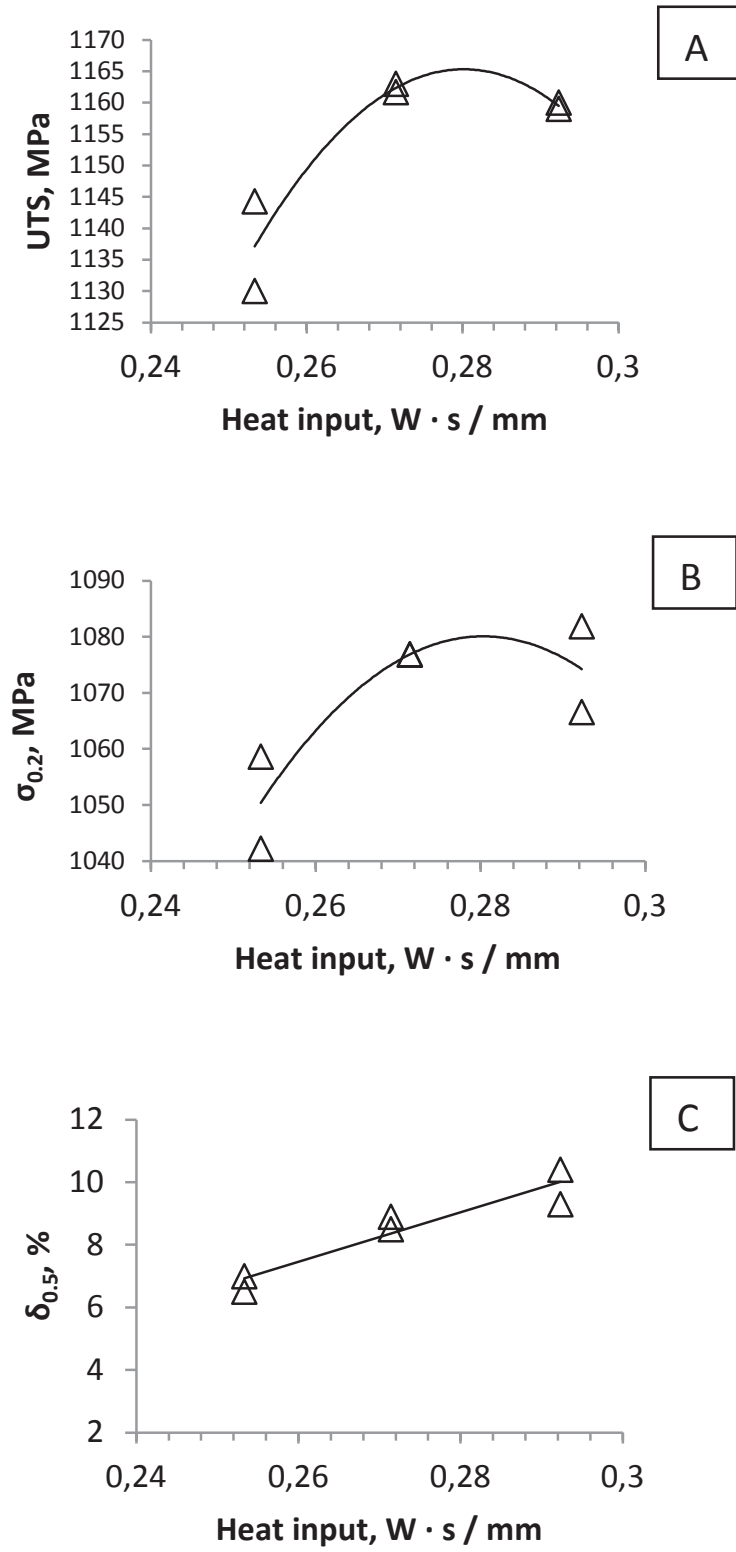

Fig. 6. Tensile strength (A), yield strength (B) и elongation (C) of the test samples.

Metallographic study revealed areas of heterogeneous distribution of chemical elements of the basic composition.

The increase of a heat input in the melt zone is accompanied by a decrease of the size of liquation, 
which indicates an improvement in the quality of melting. This fact can be explained by the dispersion of the powder used. After annealing on the sections, traces of dispersoids of intermetallic compounds that promote hardening of the metal are discernible (Figure 7).
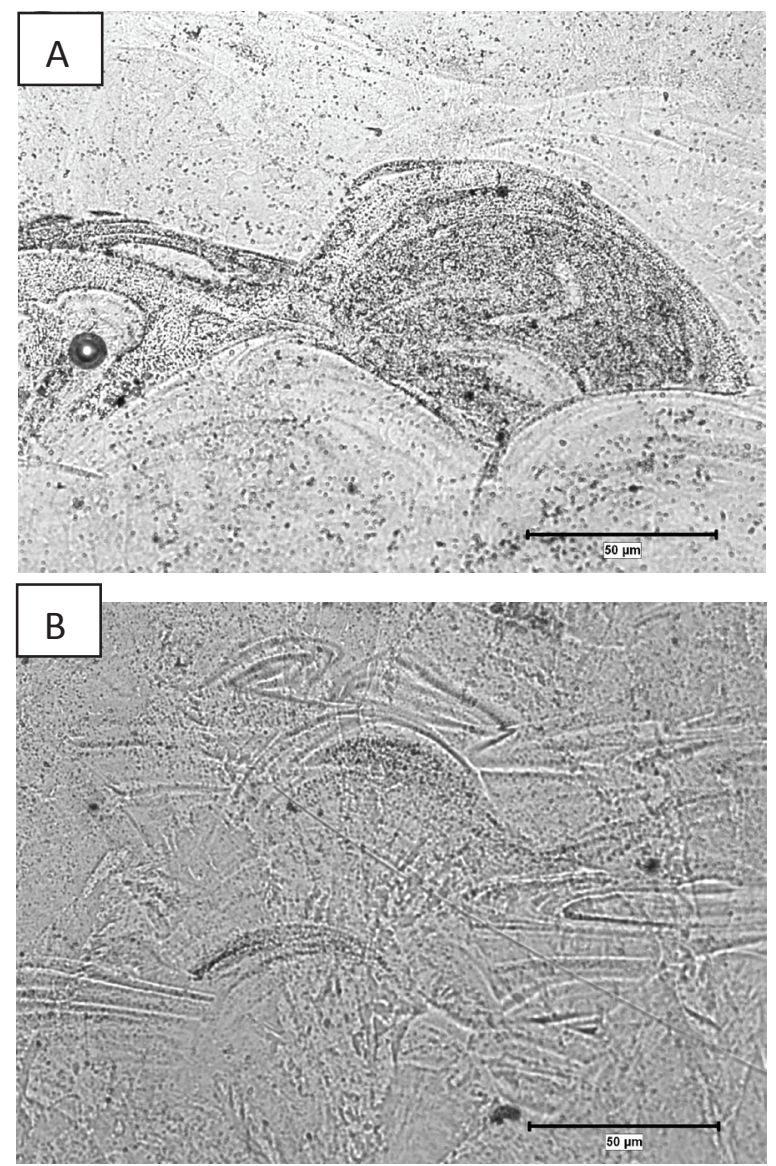

Fig. 7. Structure of selective laser melted samples without annealing (A) and after quenching (B).

\section{Conclusions}

1. As the heat input in the melting zone increases, the quality of alloy melting improves, and the effect of anisotropy decreases.

2. According to the data of dynamic bending and uniaxial stretching of samples, the complex of mechanical properties of the resulting melted alloy depends on the chemical composition of the powder material.

3. The mechanical characteristics of the steel obtained by selective laser melting of the powder composition MS1 are subject to the influence of subsequent heat treatment (annealing, aging).

4. In the technology of selective laser melting, the properties of the resulting melted alloy depend not only on the heat input, but also on the dispersion of the powder used.

This work was supported by the grant of Russian Scientific Fund №15-19-00210. Experimental studies were performed on the equipment of the collective use center "Composition, Structure and Properties of Structural Materials" NRC
"Kurchatov Institute" - CRISM "Prometey", Saint-Petersburg, Russia.

\section{References}

1. Giedeon N. Levy The role and future of the laser technology in the additive manufacturing environment, Physics Procedia 5, 65-80 (2010)

2. A. Hussein, L. Hao, Advanced lattice support structures for metal additive manufacturing, Journal of Materials Processing Technology 213, 10191026 (2013)

3. Di Wang, Y. Yang, Study on the designing rules and processability of porous structure based on selective laser melting (SLM), Journal of Materials Processing Technology 213, 1734-1742 (2013)

4. V.P. Perevertov, I.K. Andronchev, M.M. Abulkasimov, Technologies of processing materials by concentrated energy flow, Reliability and quality of complex systems, $\mathbf{3}$ / 11, 69-79 (2015)

5. P. Hanzl, M. Zetek The Influence of Processing Parameters on the Mechanical Properties of SLM Parts, Procedia Engineering 100, 1405-1413 (2015)

6. P. Li Constitutive and failure behaviour in selective laser melted stainless steel for microlattice structures, Materials Science \& Engineering A 622, 114-120 (2015)

7. J. Sedlaka, D. Rican Study of Materials Produced by Powder Metallurgy Using Classical and Modern Additive Laser Technology, Procedia Engineering 100, 1232-1241 (2015)

8. K. Saeidi, X. Gao, Y. Zhong, Z.J. Shen Hardened austenite steel with columnar sub-grain structure formed by laser melting, Materials Science \& Engineering A 625, 221-229 (2015)

9. M.L. Bernstein, A.G. Rakhshtadt Metallurgy and heat treatment of steel Reference book. In 3 volumes. (Mashinostroenye, Moscow, 1983)

10. L.V. Tarasenko, M.V. Unchikova. Mechanical properties of corrosion-resistant steel after double aging Engineering Journal: Science and Innovation 3 (2013) 